\title{
Lymph node ratio is an independent prognostic factor for patients after resection of pancreatic cancer
}

Han-xiang Zhan, Jian-wei Xu, Lei Wang, Guang-yong Zhang and San-yuan Hu*

\begin{abstract}
Background: The prognostic value of lymph node ratio (LNR) in pancreatic cancer remains controversial. In the current retrospective study, we assessed the value of LNR on predicting the survival of postoperative patients with pancreatic cancer.

Methods: Medical records of patients who underwent pancreatic resection for pancreatic cancer in the department of general surgery, Qilu Hospital, Shandong University were reviewed retrospectively. Demographic,

clinicopathological, tumor-specific data, and histopathological reports were collected. Univariate and multivariate survival analyses were performed.

Results: A total of 83 patients with pancreatic cancer were collected. The mean number of examined LN was $8.2 \pm$ 6.1 (0 to 26). Differential degree (low) $(P=0.019$, hazard ratio $(H R)=2.276,95 \%$ confidence interval (Cl): 1.171 to 4.424) and $L N R>0.2(P=0.018, H R=2.685,95 \% \mathrm{Cl}: 1.253$ to 5.756$)$ were independent adverse prognostic factors according to the multivariate survival analysis.
\end{abstract}

Conclusions: Our study indicated that LNR $>0.2$ was an independent adverse prognostic factor for pancreatic cancer, which may provide important information for prognostic assessment.

Keywords: Pancreatic cancer, Lymph node ratio, Prognosis, Surgery

\section{Background}

Pancreatic cancer is the fourth most frequent cause of cancer death in the United States with an overall 5-year survival rate of $5 \%$ [1]. Only $20 \%$ of cases can be resected when diagnosed. However, the 5-year survival rate is reported to range only between $15 \%$ and $25 \%$ [2].

Several factors are related to the prognostic outcome of patients with resection of pancreatic cancer, including tumor stage, histologic differentiation, tumor size, lymph node (LN) status, and resection margin status [3]. Of them, the prognostic value of LN status is always controversial. Several studies have demonstrated that LN metastasis is associated with poor prognosis of patients with pancreatic cancer, whereas some other studies have not observed the associations between LN metastasis and survival outcomes [4].

\footnotetext{
* Correspondence: husanyuan1962@hotmail.com

Department of General Surgery, Qilu hospital, Shandong University, No. 107, Wenhua West Road, Lixia District, Jinan, Shandong Province 250012, China
}

To assess the prognostic value of $\mathrm{LN}$ involvement better, the importance of lymph node ratio (LNR) has been highlighted, which is determined by dividing the total number of metastatic LNs by the total number of examined LNs [5]. Many studies have identified that LNR is a valuable prognostic factor in pancreatic cancer patients [5]. Nevertheless, its prognostic value in node-positive patients has not been shown in other studies [4]. Additionally, the cutoff values of LNR are inconsistent in different studies. LNR $\geq 0.2,0.15$, and 0.1 have all been reported as an independent poor predictive factor [6-9].

The current study aimed to assess the prognostic value of LNR in postoperative patients with pancreatic cancer.

\section{Methods}

This study has been approved by the ethics committee on scientific research of Shandong University, Qilu Hospital and has been performed in accordance with the ethical standards 
and according to the Declaration of Helsinki. Written informed consent was obtained from all subjects.

A series of 83 patients who underwent resection for pancreatic cancer in the department of general surgery, Qilu Hospital, Shandong University was collected for analysis. Surgical procedures were conducted by senior surgeons. Medical records were reviewed retrospectively, and demographic, clinicopathological, tumor-specific data, and histopathological reports were collected. TNM staging was defined according to the National Comprehensive Cancer Network (NCCN) Clinical Practice Guidelines in Oncology (NCCN Guidelines ${ }^{\circ}$ ) Pancreatic Adenocarcinoma Version 1, 2014 (http://www.nccn.org/ professionals/physician_gls/f_guidelines.asp). Follow-up data were acquired from hospital records supplemented with telephone contact. The end point was overall survival. Survival time was calculated according to the date of death or as the time between the last follow-up date and the operation date.

Statistical analysis was conducted using SPSS v.13.0 software (SPSS Inc., Chicago, IL, USA). A value of $P<$ 0.05 was considered as statistically significant. Graphs were produced by GraphPad Prism 5 Software (GraphPad, San Diego, CA, USA). The Kaplan-Meier method and Cox regression were used for univariate and multivariate survival analyses, respectively.

\section{Results}

\section{The clinicopathologic characteristics of patients}

A total of 83 patients with pancreatic cancer were collected in the current study, including 53 males and $30 \mathrm{fe}-$ males, with an average age of $61.7 \pm 10.7$ (range 36 to 85) years old. The average size of the tumor diameter was $4.6 \pm$ $2.23 \mathrm{~cm}$ (range 0.5 to $14 \mathrm{~cm}$ ). The total number of examined LNs was range from 0 to 26 , with a mean of $8.2 \pm$ 6.1. The average follow-up was 26.9 months (median 15, range 1 to 87 months).

\section{Univariate and multivariate survival analyses}

The median survival was 20 months. The overall 1 - and 3 -year survival rates were $58.6 \%$ and $42.7 \%$, respectively. Univariate survival analysis indicated that sex, differential degree, LN staging, TNM staging, LNR, and total number of examined LNs were potential prognostic factors (Table 1, Figure 1). Multivariate analysis demonstrated that differential degree (low) and LNR $>0.2$ were independent adverse prognostic factors $(P=0.019$, hazard ratio $(\mathrm{HR})=2.276,95 \%$ confidence interval $(\mathrm{CI}): 1.171$ to 4.424; $P=0.018, \mathrm{HR}=2.685,95 \% \mathrm{CI}: 1.253$ to 5.756 ) (Table 2).

\section{Discussion}

LN involvement remains one of the most important factors for predicating survival of patients with resection of
Table 1 Univariate analysis of factors predictive of poor overall survival

\begin{tabular}{|c|c|c|c|c|}
\hline \multirow[t]{2}{*}{ Variables } & \multirow{2}{*}{$\begin{array}{l}\text { Case } \\
\text { number }(n)\end{array}$} & \multicolumn{3}{|c|}{ Univariate analysis } \\
\hline & & $\begin{array}{l}\text { Overall survival } \\
\text { (median } \pm \mathrm{SE}, \\
\text { months) }\end{array}$ & $\begin{array}{l}\text { 1-year } \\
\text { survival } \\
\text { rate (\%) }\end{array}$ & $\begin{array}{l}P \\
\text { value }\end{array}$ \\
\hline Sex & & & & 0.041 \\
\hline Male & 53 & $15 \pm 3.4$ & 54.5 & \\
\hline Female & 30 & $54 \pm 11.0$ & 65.9 & \\
\hline Age(years old) & & & & 0.718 \\
\hline$<65$ & 50 & $20 \pm 9.6$ & 62.0 & \\
\hline$\geq 65$ & 33 & $33 \pm 15.9$ & 53.2 & \\
\hline Diabetes & & & & 0.168 \\
\hline No & 74 & $23 \pm 10.8$ & 61.9 & \\
\hline Yes & 9 & $10 \pm 1.5$ & 33.3 & \\
\hline Locations & & & & 0.353 \\
\hline Head & 52 & $31 \pm 14.8$ & 63.1 & \\
\hline Body-tail & 31 & $15 \pm 4.7$ & 51.6 & \\
\hline Tumor size $(\mathrm{cm})$ & & & & 0.606 \\
\hline$\leq 3$ & 12 & $20 \pm 7.4$ & 63.6 & \\
\hline$>3$ & 70 & $23 \pm 11.0$ & 57.3 & \\
\hline Differential degree ${ }^{a}$ & & & & 0.039 \\
\hline High/moderate & 55 & $33 \pm 12.8$ & 66.3 & \\
\hline Low & 22 & $10 \pm 1.4$ & 40.8 & \\
\hline Tumor staging & & & & 0.664 \\
\hline $\mathrm{T} 1 / \mathrm{T} 2$ & 69 & $18 \pm 9.6$ & 57.3 & \\
\hline $\mathrm{T} 3 / \mathrm{T} 4$ & 14 & $23 \pm 13.7$ & 64.3 & \\
\hline Lymph node staging & & & & 0.041 \\
\hline No & 53 & $33 \pm 14.1$ & 69.0 & \\
\hline $\mathrm{N} 1$ & 30 & $11 \pm 1.3$ & 39.7 & \\
\hline TNM staging & & & & 0.014 \\
\hline$|/| \mid$ & 41 & $54 \pm 15.5$ & 72.1 & \\
\hline III/IV & 42 & $11 \pm 3.1$ & 45.5 & \\
\hline Perineuronal invasion & & & & 0.082 \\
\hline No & 48 & $43 \pm 22.8$ & 69.4 & \\
\hline Yes & 35 & $11 \pm 1.0$ & 44.4 & \\
\hline LNR & & & & 0.001 \\
\hline$\leq 0.2$ & 66 & $33 \pm 13.6$ & 69.0 & \\
\hline$>0.2$ & 17 & $8 \pm 1.1$ & 13.8 & \\
\hline $\begin{array}{l}\text { Total number } \\
\text { of examined LNs }\end{array}$ & & & & 0.062 \\
\hline$<12$ & 61 & $15 \pm 4.3$ & 53.4 & \\
\hline$\geq 12$ & 22 & $55 \pm$ None $^{b}$ & 74.9 & \\
\hline
\end{tabular}

The differential degree of six cases is not recorded. ${ }^{\mathrm{b}}$ None: if the number of censored data is more than $50 \%$ of the total, median survivals cannot be calculated by SPSS. LN, lymph node; SE, standard error. 
Lymph node ratio (LNR)

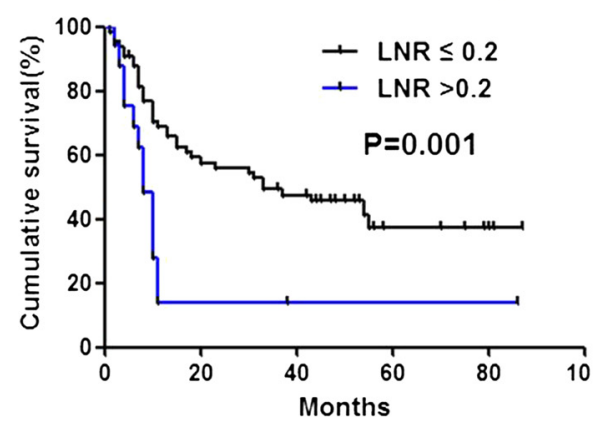

Total number of examined LNs

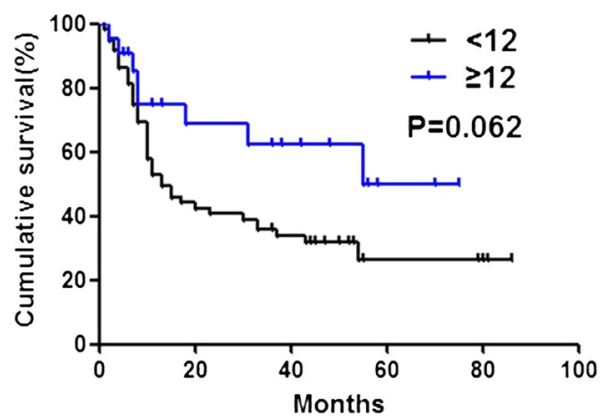

Figure 1 Kaplan-Meier survival curves. Left panel, survival analysis based on LNR. Right panel, survival analysis based on the total number of examined LN. LN, lymph node; LNR, lymph node ratio.

pancreatic cancer $[5,10]$. However, both $\mathrm{LN}$ status and the numbers of examined LNs are imperfect as the sole predictor. LNR not only provides information regarding the number of positive LNs but also gives an estimate of the adequacy of LNs obtained [9], which is a significant modifier of the effect of LN status and the numbers of examined LNs on survival of patients with resected cancer [11]. LNR has been identified as a tool to predict outcome in cancers of the esophagus [12], stomach [13], colon [14], and ampulla of Vater [15]. However, the association of LNR and overall survival in pancreatic cancer has not been well defined. We showed that LNR is negatively correlated with the overall survival with a cutoff value of 0.2.

There is no consensus on the best cutoff value for LNR. Pawlik and colleagues used categories of LNR $<0.2,0.4$, and $>0.4$ [16], while House et al. used 0.18 as a cutoff value [17]. Ashfaq et al. indicated that LNR cutoff of 0.1 was statistically significant for survival discrimination [9]. Our study demonstrated that patients with LNR $>0.2$ displayed poor prognosis, as reported by previous studies [6,7].

In addition, we evaluated the prognostic role of examined LNs, which indicated that total number of examined LNs $\geq 12$ was potentially associated with improved survival. Several studies have reported the link between longer survival and total number of examined LNs [18,19]. Our study might also indicate that standard lymphadenectomy is enough,

Table 2 Multivariate analysis of factors predictive of poor overall survival

\begin{tabular}{llll}
\hline Variables & $\begin{array}{l}\text { Hazard } \\
\text { ratio }\end{array}$ & $\begin{array}{l}\text { 95\% confidence } \\
\text { interval }\end{array}$ & P value \\
\hline LNR (>0.2) & 2.685 & 1.253 to 5.756 & 0.018 \\
Differential degree (low) & 2.276 & 1.171 to 4.424 & 0.019 \\
Sex (female) & 0.578 & 0.298 to 1.124 & 0.094 \\
Lymph node staging (N1) & 0.761 & 0.284 to 2.042 & 0.717 \\
TNM staging (III/IV) & 1.5 & 0.772 to 2.914 & 0.229 \\
\hline
\end{tabular}

LNR, lymph node ratio. because the mean number of LNs resected in patients with pancreatic cancer who underwent standard lymphadenectomy in the randomized controlled trials (RCTs) was 13 to 17 [20-22]. Extended lymphadenectomy increases the total number of examined LNs, but there are no significant differences in the overall survival between patients who underwent pancreatic cancer surgery with extended lymphadenectomy and those who underwent operation with standard lymphadenectomy [23,24]. On the contrary, extended lymphadenectomy may increase postoperative morbidities and mortalities and decrease quality of life $[24,25]$. Although there was a debate on the value of extended lymphadenectomy in the past, the ideas are beginning to converge. Unnecessary extended lymphadenectomy should be avoided, which has been recommended by the NCCN Clinical Practice Guidelines in Oncology (NCCN Guidelines ${ }^{\circ}$ ) Pancreatic Adenocarcinoma Version 1, 2014.

Both the LN status and the LNR are influenced by the total LN harvested [10]. Valsangkar and colleagues analyzed 14,907 patients in a national database and 902 patients treated at a single large institution, which showed that a minimum of 13 to 16 LNs must be examined to accurately predict survival [10]. The mean number of the total examined LN was $8.2 \pm 6.1$ in our study, which might not do full justice to the prognostic value of LNR. Nevertheless, a moderate number (6 to $12 \mathrm{LNs}$ ) of the total examined LN could partly predict survival [10]. What we need to emphasize is that the retrieval of the lymph nodes not only depends on the scope of the lymphadenectomy but also depends on the seriousness of the pathologist. Only surgeons and pathologists cooperated closely may accurately evaluate the value of LNR.

\section{Conclusions}

The present study demonstrated that LNR $>0.2$ was an independent adverse prognostic factor, which is powerful and useful for prognostic assessment for pancreatic cancer. 


\section{Abbreviations}

LN: lymph node; LNR: lymph node ratio.

\section{Competing interests}

The authors declare that they have no competing interests.

\section{Authors' contributions}

$H X Z$, JWX, and SYH proposed the study. HXZ and JWX wrote the first draft and collected and analyzed the data. All authors contributed to the design and interpretation of the study and to further drafts. LW, GYZ, and SYH revised the manuscript. All authors read and approved the final manuscript.

\section{Acknowledgements}

This work was supported by China Postdoctoral Science Foundation (2013 M531606) and Shandong Provincial Natural Science Foundation, China (ZR2013HQ049).

Received: 8 September 2014 Accepted: 12 February 2015

Published online: 13 March 2015

\section{References}

1. Siegel R, Ma J, Zou Z, Jemal A. Cancer statistics, 2014. CA Cancer J Clin. 2014;64:9-29.

2. Winter JM, Cameron JL, Campbell KA, Arnold MA, Chang DC, Coleman J, et al. 1423 pancreaticoduodenectomies for pancreatic cancer: a singleinstitution experience. J Gastrointest Surg. 2006;10:1199-210. discussion 1210-1191.

3. Brennan MF, Kattan MW, Klimstra D, Conlon K. Prognostic nomogram for patients undergoing resection for adenocarcinoma of the pancreas. Ann Surg. 2004;240:293-8.

4. Kang MJ, Jang JY, Chang YR, Kwon W, Jung W, Kim SW. Revisiting the concept of lymph node metastases of pancreatic head cancer: number of metastatic lymph nodes and lymph node ratio according to $\mathrm{N}$ stage. Ann Surg Oncol. 2014;21:1545-51.

5. Fujii T. Extended lymphadenectomy in pancreatic cancer is crucial. World J Surg. 2013;37:1778-81.

6. Yamamoto $Y$, Ikoma H, Morimura R, Konishi H, Murayama Y, Komatsu S, et al. The clinical impact of the lymph node ratio as a prognostic factor after resection of pancreatic cancer. Anticancer Res. 2014;34:2389-94.

7. Shamseddine Al, Mukherji D, Melki C, Elias E, Eloubeidi M, Dimassi H, et al. Lymph node ratio is an independent prognostic factor after resection of periampullary malignancies: data from a tertiary referral center in the middle East. Am J Clin Oncol. 2014;37:13-8.

8. Robinson SM, Rahman A, Haugk B, French JJ, Manas DM, Jaques BC, et al. Metastatic lymph node ratio as an important prognostic factor in pancreatic ductal adenocarcinoma. Eur J Surg Oncol. 2012;38:333-9.

9. Ashfaq A, Pockaj BA, Gray RJ, Halfdanarson TR, Wasif N. Nodal counts and lymph node ratio impact survival after distal pancreatectomy for pancreatic adenocarcinoma. J Gastrointest Surg. 2014;18(11):1929-35.

10. Valsangkar NP, Bush DM, Michaelson JS, Ferrone CR, Wargo JA, Lillemoe KD, et al. NO/N1, PNL, or LNR? The effect of lymph node number on accurate survival prediction in pancreatic ductal adenocarcinoma. J Gastrointest Surg. 2013;17:257-66.

11. Smith BJ, Mezhir JJ. An interactive Bayesian model for prediction of lymph node ratio and survival in pancreatic cancer patients. J Am Med Inform Assoc. 2014;21(e2):e203-11.

12. Mariette C, Piessen G, Briez N, Triboulet JP. The number of metastatic lymph nodes and the ratio between metastatic and examined lymph nodes are independent prognostic factors in esophageal cancer regardless of neoadjuvant chemoradiation or lymphadenectomy extent. Ann Surg. 2008;247:365-71.

13. Lee SY, Hwang I, Park YS, Gardner J, Ro JY. Metastatic lymph node ratio in advanced gastric carcinoma: a better prognostic factor than number of metastatic lymph nodes? Int J Oncol. 2010;36:1461-7.

14. Chen SL, Steele SR, Eberhardt J, Zhu K, Bilchik A, Stojadinovic A. Lymph node ratio as a quality and prognostic indicator in stage III colon cancer. Ann Surg. 2011:253:82-7.

15. Lee JH, Lee KG, Ha TK, Jun YJ, Paik SS, Park HK, et al. Pattern analysis of lymph node metastasis and the prognostic importance of number of metastatic nodes in ampullary adenocarcinoma. Am Surg. 2011;77:322-9.
16. Pawlik TM, Gleisner AL, Cameron JL, Winter JM, Assumpcao L, Lillemoe KD, et al. Prognostic relevance of lymph node ratio following pancreaticoduodenectomy for pancreatic cancer. Surgery. 2007;141:610-8.

17. House MG, Gonen M, Jarnagin WR, D'Angelica M, DeMatteo RP, Fong Y, et al. Prognostic significance of pathologic nodal status in patients with resected pancreatic cancer. J Gastrointest Surg. 2007;11:1549-55.

18. Hellan M, Sun CL, Artinyan A, Mojica-Manosa P, Bhatia S, Ellenhorn JD, et al. The impact of lymph node number on survival in patients with lymph node-negative pancreatic cancer. Pancreas. 2008;37:19-24.

19. Slidell MB, Chang DC, Cameron JL, Wolfgang C, Herman JM, Schulick RD, et al. Impact of total lymph node count and lymph node ratio on staging and survival after pancreatectomy for pancreatic adenocarcinoma: a large, population-based analysis. Ann Surg Oncol. 2008;15:165-74.

20. Farnell MB, Pearson RK, Sarr MG, DiMagno EP, Burgart $L$, Dahl TR, et al. A prospective randomized trial comparing standard pancreatoduodenectomy with pancreatoduodenectomy with extended lymphadenectomy in resectable pancreatic head adenocarcinoma. Surgery. 2005;138:618-28. discussion 628-630.

21. Pedrazzoli S, DiCarlo V, Dionigi R, Mosca F, Pederzoli P, Pasquali C, et al. Standard versus extended lymphadenectomy associated with pancreatoduodenectomy in the surgical treatment of adenocarcinoma of the head of the pancreas: a multicenter, prospective, randomized study. Lymphadenectomy Study Group. Ann Surg. 1998;228:508-17.

22. Yeo CJ, Cameron JL, Lillemoe KD, Sohn TA, Campbell KA, Sauter PK, et al. Pancreaticoduodenectomy with or without distal gastrectomy and extended retroperitoneal lymphadenectomy for periampullary adenocarcinoma, part 2: randomized controlled trial evaluating survival, morbidity, and mortality. Ann Surg. 2002;236:355-66. discussion 366-358.

23. Jang JY, Kang MJ, Heo JS, Choi SH, Choi DW, Park SJ, et al. A prospective randomized controlled study comparing outcomes of standard resection and extended resection, including dissection of the nerve plexus and various lymph nodes, in patients with pancreatic head cancer. Ann Surg. 2014;259:656-64.

24. Sergeant G, Melloul E, Lesurtel M, Deoliveira ML, Clavien PA. Extended lymphadenectomy in patients with pancreatic cancer is debatable. World J Surg. 2013;37:1782-8.

25. Ke K, Chen W, Chen Y. Standard and extended lymphadenectomy for adenocarcinoma of the pancreatic head: a meta-analysis and systematic review. J Gastroenterol Hepatol. 2014;29:453-62.

\section{Submit your next manuscript to BioMed Central and take full advantage of:}

- Convenient online submission

- Thorough peer review

- No space constraints or color figure charges

- Immediate publication on acceptance

- Inclusion in PubMed, CAS, Scopus and Google Scholar

- Research which is freely available for redistribution 